\title{
UMA ABORDAGEM DA EXTENSÃO UNIVERSITÁRIA NA MELHORIA DA QUALIDADE DO LEITE NA CADEIA PRODUTIVA DO MUNICÍPIO DE BARBOSA FERRAZ (PARANÁ)
}

\author{
ELIDA SIMONE GUIDO * \\ ERIC DIEGO PICININ DA SILVA ** \\ MARIA CRISTINADA SILVA *** \\ KATIUCHIA PEREIRATAKEUCHI $* \star * *$ \\ ELIANE DALVA GODOY DANESI *****
}

\begin{abstract}
Este trabalho teve como principais objetivos difundir práticas de higiene e avaliar a sua eficácia na redução da contaminação microbiológica do leite. Efetuou-se mapeamento da linha de processamento do leite pasteurizado para identificar os principais pontos de contaminação e eliminá-los com a adoção de Boas Práticas de Fabricação. Realizou-se levantamento de dados nas propriedades produtoras de leite e no estabelecimento processador, mediante listas de verificação. Ministrou-se treinamento nas propriedades rurais com ênfase nas Boas Práticas de Produção, seguido da coleta de amostras de leite cru e de esfregaço da superfície das mãos dos ordenhadores e dos latões para determinações microbiológicas, antes e após a implantação de práticas de higiene. No estabelecimento processador foram coletadas 5 amostras de leite em diferentes pontos da linha de processamento e 1 pacote de leite pasteurizado tipo $\mathrm{C}$. Os resultados mostraram que dos 9 itens relacionados à higiene diagnosticados nas 17 propriedades rurais, 5 (55\%) apresentaram não conformidade com as normas. As amostras coletadas após a implantação das práticas de higiene apresentaram redução da elevada carga microbiana verificada anteriormente. Dos 142 itens avaliados pela lista de verificação aplicada no estabelecimento processador, 38\% apresentaram conformidade. A provável origem da contaminação localizou-se após a saída do tanque isotérmico. Comprovou-se a eficácia da adoção das Boas Práticas de Produção na redução da contaminação microbiológica do leite cru, bem como a necessidade de adequação do estabelecimento processador às normas de Boas Práticas de Fabricação.
\end{abstract}

PALAVRAS-CHAVE: LEITE; SEGURANÇA ALIMENTAR; BOAS PRÁTICAS DE FABRICAÇÃO; CONTAMINAÇÃO MICROBIOLÓGICA.

\footnotetext{
* Tecnóloga em Alimentos, Universidade Estadual de Maringá (UEM), Umuarama, PR (e-mail: elidaguido23@hotmail.com).

** Tecnólogo em Alimentos, UEM, Umuarama, PR (e-mail: ericpicinin@gmail.com).

*** Tecnóloga em Alimentos, UEM, Umuarama, PR (e-mail: sarafinacristina@hotmail.com).

**** Professora, Doutora em Engenharia de Alimentos, Escola de Agronomia e Engenharia de Alimentos, Universidade Federal de Goiás (EA-UFG), Goiânia, GO (e-mail: katiuchia.takeuchi@gmail.com).

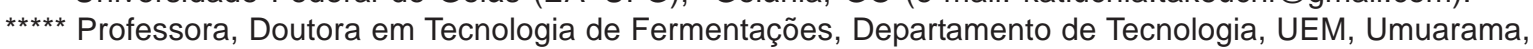
PR (e-mail: hdanesi@terra.com.br).
} 


\section{INTRODUÇÃO}

O leite constitui excelente substrato para o crescimento de grande diversidade de microorganismos e se for proveniente de animais sadios e ordenhados de forma asséptica deve apresentar reduzido número de micro-organismos contaminantes, mas posteriormente podem ocorrer contaminações a partir do ambiente e do homem (TRONCO, 2003).

O controle microbiológico do leite é realizado, principalmente, por meio da pesquisa de microorganismos indicadores, que quando presentes podem fornecer informações sobre a ocorrência de contaminação fecal, a provável presença de patógenos ou sobre sua deterioração potencial (FRANCO e LANDGRAF, 2002).

Determinados micro-organismos ou grupos de micro-organismos são utilizados como indicadores das condições higiênico-sanitárias de produtos e processos. Entre esses, destacamse a quantificação de coliformes totais e fecais, a contagem total de micro-organismos mesófilos aeróbios, a enumeração de estafilococos coagulase positiva e a enumeração de bolores e leveduras (HAJDENWURCEL, 1998).

As bactérias estafilococos coagulase positiva são encontradas na cavidade nasal e na pele de pessoas e de animais. Além da contaminação por intermédio dos manipuladores, essa bactéria pode ser introduzida nos produtos alimentícios a partir de equipamentos e utensílios usados no processo (LOPES, 2007). A presença de número elevado dessas bactérias indica perigo potencial para a saúde pública, devido à enterotoxina estafilocócica (FRANCO e LANDGRAF, 2002). Além disso, essa toxina é termorresistente, o que constitui ponto crucial no controle de qualidade de alimentos (BORELLI, 2006). A contagem de bactérias aeróbias mesófilas também é comumente empregada para indicar a qualidade sanitária dos alimentos (FRANCO e LANDGRAF, 2002).

Tendo em vista a importância econômica da cadeia leiteira, o valor nutricional do alimento e os problemas relacionados à sua qualidade no Brasil, o Ministério da Agricultura, Pecuária e Abastecimento (MAPA) publicou a Instrução Normativa $n^{\circ}$ 51. Tal IN estabeleceu novos parâmetros físico-químicos e microbiológicos para o leite, além da exigência da refrigeração do mesmo na própria propriedade rural e no seu transporte a granel para a indústria (BRASIL, 2002a).

A qualidade dos produtos derivados do leite dependerá, basicamente, das condições microbiológicas da matéria-prima (FRANCO e LANDGRAF, 2002).

Para controlar a contaminação microbiológica, o produtor deve adotar as Boas Práticas de Produção que incluem: manter o local de ordenha sempre limpo, utilizar água potável, lavar as mãos e mantê-las limpas durante a ordenha, imergir os tetos em solução desinfetante antes e após a ordenha, secar os tetos com papel toalha descartável e lavar os equipamentos e utensílios após cada ordenha, entre outras (DÜRR, 2005). A contaminação do leite pode ocorrer durante a ordenha, mas as principais fontes são os equipamentos utilizados durante a manipulação, transporte, processamento e o armazenamento (FRANCO e LANDGRAF, 2002).

Em alimentos processados, a presença de número considerável de coliformes ou enterobactérias indica processamento inadequado e/ou recontaminação pós-processamento (FRANCO e LANDGRAF, 2002). Devido a esse fato, a cadeia produtiva leiteira deve também adotar as Boas Práticas de Fabricação que nas indústrias de alimentos são consideradas como etapas fundamentais no controle das condições higiênico-sanitárias de modo a garantir a produção de alimentos seguros (LOPES, 2007).

O presente trabalho foi desenvolvido no município de Barbosa Ferraz (PR), como atividade do projeto de extensão do Programa Universidade sem Fronteiras "Difusão e Implantação de Boas Práticas de Fabricação e Gestão da Segurança Alimentar na Cadeia Agroindustrial do Leite". Seus objetivos foram difundir práticas de higiene e avaliar a eficácia das mesmas na redução da contaminação microbiológica do leite cru ordenhado manualmente, visando atender a legislação vigente. Além disso, efetuou-se o mapeamento da linha de processamento do leite pasteurizado pela Associação dos 
Produtores do município para identificar os principais pontos de contaminação e eliminá-los por meio da adoção de procedimentos de Boas Práticas de Fabricação.

\section{MATERIAL E MÉTODOS}

\subsection{LEVANTAMENTO DE DADOS}

Os dados que constam neste trabalho foram obtidos pela equipe do projeto de extensão, diretamente nas propriedades produtoras e no estabelecimento processador do leite do município de Barbosa Ferraz (PR).

Primeiramente, realizou-se o diagnóstico de 17 propriedades produtoras de leite por meio da Lista de Verificação para Monitoramento da Qualidade do Leite na Propriedade. Analisaram-se diversos itens referentes à infra-estrutura, ordenha, limpeza dos equipamentos e utensílios, sanidade e nutrição animal, selecionados com base nas normas de Boas Práticas de Produção e Instrução Normativa nº. 51, do Ministério da Agricultura, Pecuária e Abastecimento (BRASIL, 2002a).

A avaliação do cumprimento das condições higiênico-sanitárias e de recomendações de Boas Práticas de Fabricação no estabelecimento produtor foi realizada por intermédio da Lista de Verificação das Boas Práticas de Fabricação, de acordo com a RDC n 275, de 21 de outubro de 2002, estabelecida pela Agência Nacional de Vigilância Sanitária (BRASIL, 2002b).

\subsection{COLETA DE AMOSTRAS E TREINAMENTO EM BOAS PRÁTICAS DE PRODUÇÃO}

Das 17 propriedades visitadas, quatro foram selecionadas para o desenvolvimento de estudo mais detalhado e acompanhamento dos resultados do treinamento e instruções dispensados aos manipuladores de leite.

Inicialmente, coletaram-se amostras de leite cru e de esfregaço (DOWNES e ITO, 2001) da superfície das mãos dos ordenhadores e dos latões utilizados.

Ministrou-se treinamento prático, baseado em conceitos de Boas Práticas de Produção, recomendando-se a realização dos seguintes procedimentos demonstrados durante o treinamento: organização do momento da ordenha, higienização das mãos, eliminação dos 3 primeiros jatos de leite, higienização do teto do animal antes da ordenha (pré-dipping), secagem dos tetos com papel toalha descartável, higienização do teto do animal após a ordenha (pós-dipping), alimentação dos animais após a ordenha, refrigeração do leite e lavagem dos utensílios e do local de ordenha (PEREIRA, MADEIRA e LIMA, 2006).

Efetuou-se o treinamento prático para conscientizar o produtor de que medidas simples permitem a obtenção de leite de qualidade e de acordo com os requisitos da legislação.

Para possibilitar a realização dos procedimentos de higiene na ordenha forneceu-se ao produtor, durante 1 semana, kit com todos os produtos necessários, composto por solução de iodo, detergente alcalino clorado, álcool 70\%, detergente neutro, caneca de dipping e bucha vegetal. Após esse período, foram coletadas novamente amostras de leite cru e de esfregaço da superfície das mãos dos ordenhadores e dos latões para estabelecer a comparação da contagem microbiológica antes e após o treinamento e difusão das práticas de higiene na ordenha.

No estabelecimento processador foram coletadas 5 amostras de leite em diferentes pontos da linha de processamento e 1 pacote de leite pasteurizado tipo $C$. A superfície da embalagem do leite pasteurizado foi amostrada pela técnica de esfregaço de superfície (DOWNES e ITO 2001).

Para a coleta das amostras foram utilizados frascos esterilizados de $50 \mathrm{~mL}$. Os swabs foram mantidos em tubos de ensaio com solução tampão estéril até o plaqueamento.

As amostras foram devidamente identificadas, acondicionadas em caixa isotérmica contendo 
gelo reciclável, e encaminhadas ao Laboratório de Microbiologia do Centro de Tecnologia da Universidade Estadual de Maringá, Campus de Umuarama (PR).

\subsection{ANÁLISES MICROBIOLÓGICAS}

Os procedimentos de amostragem, assim como as determinações microbiológicas, foram realizados de acordo com as recomendações de DOWNES e ITO (2001) e SILVA, JUNQUEIRA e SILVEIRA (1997).

Utilizou-se para a determinação do número mais provável (NMP) de coliformes totais e coliformes termotolerantes a técnica dos tubos múltiplos.

A análise presuntiva de coliformes foi realizada em tubos contendo Caldo Lauril Sulfato de Sódio em concentração dupla (LST), com tubos de Durham invertidos e incubados por 48 horas a $35^{\circ} \mathrm{C}$. Uma alçada de cada tubo positivo (que apresentou produção de gás no interior do tubo de Durham) foi semeada em tubos contendo Caldo Lactosado Bile Verde Brilhante (VBBL) e Caldo Escherichia coli (EC) com tubos de Durham invertidos. Os tubos contendo VBBL foram incubados a $35^{\circ} \mathrm{C}$ por 24 a 48 horas, como prova confirmatória de coliformes totais. Os tubos contendo Caldo EC foram incubados a $45^{\circ} \mathrm{C}$ por 24 horas, como prova confirmatória de coliformes termotolerantes.

A quantificação de estafilococos coagulase positiva (ECP) foi realizada utilizando-se semeadura em Agar Baird-Parker e incubação durante 48 horas a $37^{\circ} \mathrm{C}$, sendo 5 colônias características de cada placa submetidas à produção de coagulase livre.

Para a enumeração de bactérias mesófilas aeróbias utilizou-se semeadura em Ágar para Contagem Total (PCA), com incubação a $37^{\circ} \mathrm{C}$ por 24 horas.

\section{RESULTADOS E DISCUSSÃO}

Nas 17 propriedades produtoras de leite visitadas foram analisados 9 itens referentes ao manejo correto da ordenha (Figura 1), verificando-se não conformidade com as práticas de higiene recomendadas pelas normas de Boas Práticas de Produção e Instrução Normativa n 51 (BRASIL, 2002a) em 5 delas (55\%).

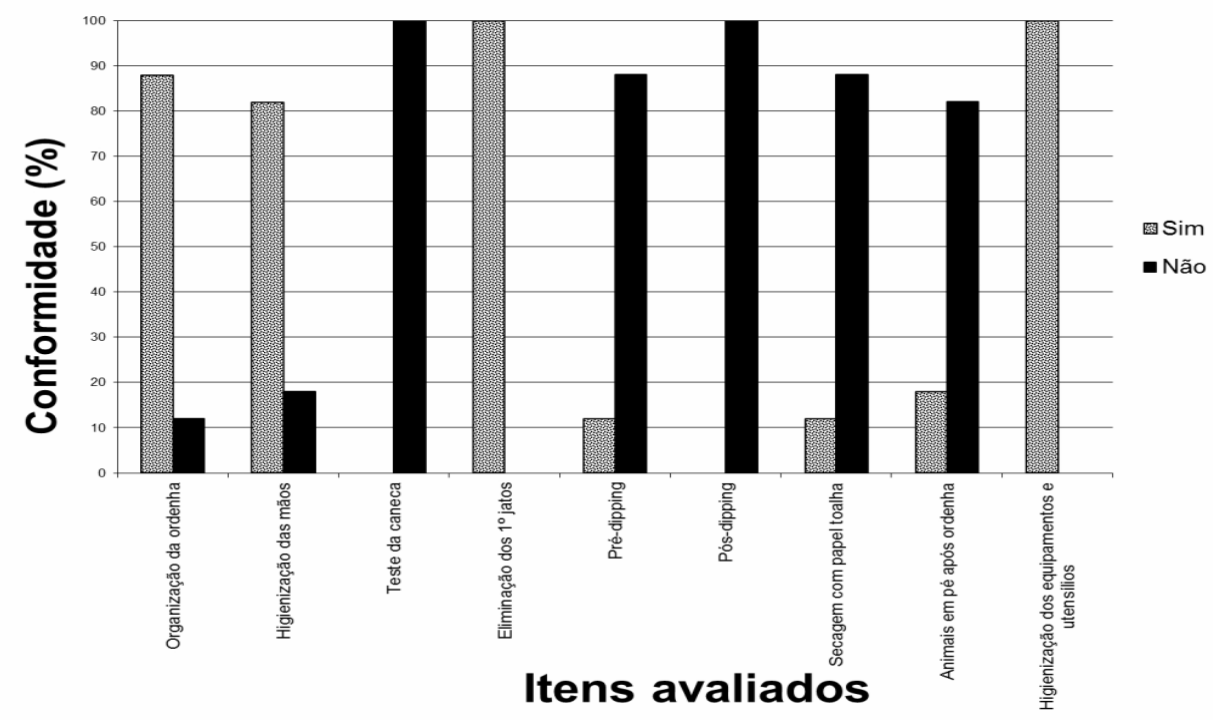

FIGURA 1 - DIAGNÓSTICO DOS ITENS RELACIONADOS ÀS BOAS PRÁTICAS NA ORDENHA NAS PROPRIEDADES DO MUNICÍPIO DE BARBOSA FERRAZ (PR) 
Segundo ARCURI et al. (2006), a obtenção do leite de vacas sadias em condições higiênicas adequadas e o seu resfriamento imediato a $4^{\circ} \mathrm{C}$ são medidas fundamentais e primárias para garantir a qualidade e segurança do leite e seus derivados.

Os dados obtidos indicam que o grande desafio a ser enfrentado pelos produtores quanto à adequação à nova legislação não está relacionado somente à saúde da glândula mamária, mas à melhoria das condições higiênicas de obtenção do produto e de sua conservação em temperaturas adequadas. Cabe ressaltar ainda o transporte de forma apropriada até as plataformas dos laticínios (OLIVEIRA, FONSECA e GERMANO, 1999).

Conforme mostram as Tabelas 1, 2 e 3, as amostras coletadas nas propriedades antes da implantação das práticas de higiene apresentaram elevada carga microbiana, principalmente o leite cru com valores acima de $2400 \mathrm{NMP} / \mathrm{mL}$ para coliformes termotolerantes. A RDC $\mathrm{n}^{\circ} 12$ (BRASIL, 2001) não estabelece padrões para coliformes em leite cru, porém esse grupo microbiano não faz parte da flora natural do leite, sendo sua presença forte indicativo de contaminação proveniente das mãos do ordenhador, dos tetos do animal e dos latões, entre outros fatores (FRANCO e LANDFGRAF, 2002).

TABELA 1 - ENUMERAÇÃO DE COLIFORMES TOTAIS E COLIFORMES TERMOTOLERANTES, MESÓFILOS AERÓBIOS E ESTAFILOCOCOS COAGULASE POSITIVA EM LEITE CRU, ANTES DA IMPLANTAÇÃO DE PRÁTICAS DE HIGIENE NA ORDENHA

\begin{tabular}{|ccccc|}
\hline ANALISES & PRODUTOR 1 & PRODUTOR 2 & PRODUTOR 3 & PRODUTOR 4 \\
Coliformes totais (NMP/mL) & $>2400$ & 1100 & 1100 & $>2400$ \\
Coliformes termotolerantes (NMP/mL) & $>2400$ & 460 & 460 & $>2400$ \\
Mesófilos aeróbios (UF C/mL) & $1 \times 10^{5}$ & $3 \times 10^{5}$ & $3,6 \times 10^{5}$ & $8,2 \times 10^{5}$ \\
Estafilococos coag. positiva (UFC/mL) & $5,6 \times 10^{3}$ & $6,5 \times 10^{3}$ & $4,5 \times 10^{3}$ & $3,8 \times 10^{3}$ \\
\hline
\end{tabular}

TABELA 2 - ENUMERAÇÃO DE COLIFORMES TOTAIS E COLIFORMES TERMOTOLERANTES, MESÓFILOS AERÓBIOS E ESTAFILOCOCOS COAGULASE POSITIVA EM MÃOS DE ORDENHADORES, ANTES DA IMPLANTAÇÃO DE PRÁTICAS DE HIGIENE NA ORDENHA

\begin{tabular}{|ccccc|}
\hline ANALISES & PRODUTOR 1 & PRODUTOR 2 & PRODUTOR 3 & PRODUTOR 4 \\
Coliformes totais (NMP/mäo) & 150 & 93 & 43 & 150 \\
Coliformes termotolerantes (NMP/mão) & 43 & 39 & 23 & 120 \\
Mésófilos aeróbios (UFC/mäo) & $4,2 \times 10^{5}$ & $3,7 \times 10^{4}$ & $1 \times 10^{4}$ & $5,3 \times 10^{5}$ \\
Estafilococos coag. positiva (UF C/mão) & $7,3 \times 10^{4}$ & $4,7 \times 10^{4}$ & $1,6 \times 10^{4}$ & $5 \times 10^{4}$ \\
\hline
\end{tabular}

\section{TABELA 3 - ENUMERAÇÃO DE COLIFORMES TOTAIS E COLIFORMES TERMOTOLERANTES, MESÓFILOS AERÓBIOS E ESTAFILOCOCOS COAGULASE POSITIVA EM LATÕES PARA ARMAZENAMENTO E TRANSPORTE DO LEITE, ANTES DA IMPLANTAÇÃO DE PRÁTICAS DE HIGIENE NA ORDENHA}

\begin{tabular}{ccccc}
\hline ANALISES & PRODUTOR 1 & PRODUTOR 2 & PRODUTOR 3 & PRODUTOR 4 \\
Coliformes totais $\left(\mathbf{N M P} / \mathbf{c m}^{2}\right)$ & 93 & 93 & 75 & 120 \\
Coliformes termotolerantes $\left(\mathbf{N M P} / \mathbf{c m}^{2}\right)$ & 43 & 39 & 39 & 93 \\
Mésófilos aeróbios $\left(\mathrm{UF} / \mathbf{c m}^{2}\right)$ & $1,2 \times 10^{4}$ & $3 \times 10^{3}$ & $1,2 \times 10^{3}$ & $5 \times 10^{4}$ \\
Estafilococos coag. positiva $\left(\mathrm{UFC} / \mathrm{cm}^{2}\right)$ & $4 \times 10^{3}$ & $2 \times 10^{3}$ & $3,5 \times 10^{3}$ & $3,2 \times 10^{3}$ \\
\hline
\end{tabular}


Analisando as Tabelas 4, 5 e 6 é possível constatar que ocorreu redução significativa da contaminação em praticamente todas as amostras coletadas após a implantação de práticas de higiene na ordenha. Esse fato condiz com a afirmação de FERREIRA (2007) de que a qualidade do leite está diretamente relacionada com o tipo de manejo adotado na produção, independentemente do nível tecnológico da propriedade e que a aplicação de Boas Práticas de Produção é essencial para a obtenção de matérias-primas de qualidade.

A conscientização do produtor rural sobre a necessidade de adotar procedimentos de Boas Práticas durante a ordenha muitas vezes ocorre de maneira gradativa e não imediata, sendo necessário o acompanhamento constante para que melhores resultados sejam observados. Em relação ao Produtor 4 verificou-se (Tabela 4, 5 e 6) pequena redução na carga microbiana das amostras coletadas, evidenciando realização incorreta e esporádica dos procedimentos de higiene necessários para a obtenção de leite de qualidade.

TABELA 4 - ENUMERAÇÃO DE COLIFORMES TOTAIS E COLIFORMES TERMOTOLERANTES, MESÓFILOS AERÓBIOS E ESTAFILOCOCOS COAGULASE POSITIVA EM LEITE CRU, APÓS A IMPLANTAÇÃO DE PRÁTICAS DE HIGIENE NA ORDENHA

\begin{tabular}{|ccccc|}
\hline ANALISES & PRODUTOR 1 & PRODUTOR 2 & PRODUTOR 3 & PRODUTOR 4 \\
Coliformes totais (NMP/mL) & 93 & 43 & 43 & 460 \\
Coliformes termotolerantes (NMP/mL) & 43 & 23 & 4 & 93 \\
Mésófilos aeróbios (UF C/mL) & $0 \times 10^{3}$ & $5 \times 10^{3}$ & $2 \times 10^{3}$ & $5 \times 10^{4}$ \\
Estafilococos coag. positiva (UFC/mL) & $2 \times 10^{3}$ & $1 \times 10^{3}$ & $1,5 \times 10^{3}$ & $2,9 \times 10^{3}$ \\
\hline
\end{tabular}

TABELA 5 - ENUMERAÇÃO DE COLIFORMES TOTAIS E COLIFORMES TERMOTOLERANTES, MESÓFILOS AERÓBIOS E ESTAFILOCOCOS COAGULASE POSITIVA EM MÃOS DE ORDENHADORES, APÓS A IMPLANTAÇÃO DE PRÁTICAS DE HIGIENE NA ORDENHA

\begin{tabular}{ccccc}
\hline ANALISES & PRODUTOR 1 & PRODUTOR 2 & PRODUTOR 3 & PRODUTOR 4 \\
Coliformes totais (NMP/mäo) & $<3$ & $\leq 3$ & $<3$ & 43 \\
Coliformes termotolerantes (NMP/mão) & $<3$ & $<3$ & $<3$ & 23 \\
Mésófilos aeróbios (UFC/mão) & $2 \times 10^{2}$ & $1,9 \times 10^{2}$ & $2 \times 10^{2}$ & $2 \times 10^{4}$ \\
Estafilococos coag. positiva (UFC/mäo) & $1,6 \times 10^{2}$ & $9,5 \times 10^{2}$ & $1,4 \times 10^{2}$ & $3 \times 10^{3}$ \\
\hline
\end{tabular}

\section{TABELA 6 - ENUMERAÇÃO DE COLIFORMES TOTAIS E COLIFORMES TERMOTOLERANTES, MESÓFILOS AERÓBIOS E ESTAFILOCOCOS COAGULASE POSITIVA EM LATÕES PARA ARMAZENAMENTO E TRANSPORTE DO LEITE, APÓS A IMPLANTAÇÃO DE PRÁTICAS DE HIGIENE NA ORDENHA}

\begin{tabular}{|ccccc|}
\hline ANÁLISES & PRODUTOR 1 & PRODUTOR 2 & PRODUTOR 3 & PRODUTOR 4 \\
Coliformes totais (NMP/ $\left./ \mathrm{cm}^{2}\right)$ & 43 & 43 & $<3$ & 93 \\
Coliformes termotolerantes $\left(\mathbf{N M P} / \mathrm{cm}^{2}\right)$ & 23 & $<3$ & $<3$ & 93 \\
Mésófilos aeróbios $\left(\mathrm{UFC} / \mathrm{cm}^{2}\right)$ & $3 \times 10^{3}$ & $1 \times 10^{3}$ & $3,5 \times 10^{2}$ & $6 \times 10^{3}$ \\
Estafilococos coag. positiva $\left(\mathbf{U F C} / \mathrm{cm}^{2}\right)$ & $1 \times 10^{3}$ & $1,3 \times 10^{2}$ & $1 \times 10^{3}$ & $1,8 \times 10^{3}$ \\
\hline
\end{tabular}


O estabelecimento processador recepciona o leite das propriedades do município e pasteuriza o "Leite do Povo" vendido em mercados, padarias e a domicílio e o "Leite das Crianças" instituído pelo Programa do Governo do Estado do Paraná, que beneficia crianças pobres de 6 a 36 meses. Devido à ocorrência de contaminações, o estabelecimento já havia encontrado barreiras para comercializar seus produtos.

Após a aplicação da Lista de Verificação da RDC nº 275 (BRASIL, 2002b) no estabelecimento processador, os itens Manipuladores e Produção/Transporte de Alimentos apresentaram 36\% e 48\%, respectivamente, de atendimento às normas (Figura 2). Nos itens relacionados às Edificações e Instalações constatou-se somente $29 \%$ de conformidade, enquanto o item Equipamentos/Móveis/ Utensílios apresentou $48 \%$ de atendimento às normas. Não houve conformidade para o item Documentação, devido à ausência da elaboração e implantação das Boas Práticas de Fabricação.

Segundo a Lista de Verificação aplicada para avaliar a conformidade dos itens em relação às Boas Práticas de Fabricação, o estabelecimento processador enquadrou-se no GRUPO 3 ( 0 a $50 \%$ de atendimento dos itens), sendo que apenas 38\% dos 142 itens avaliados apresentaram conformidade.

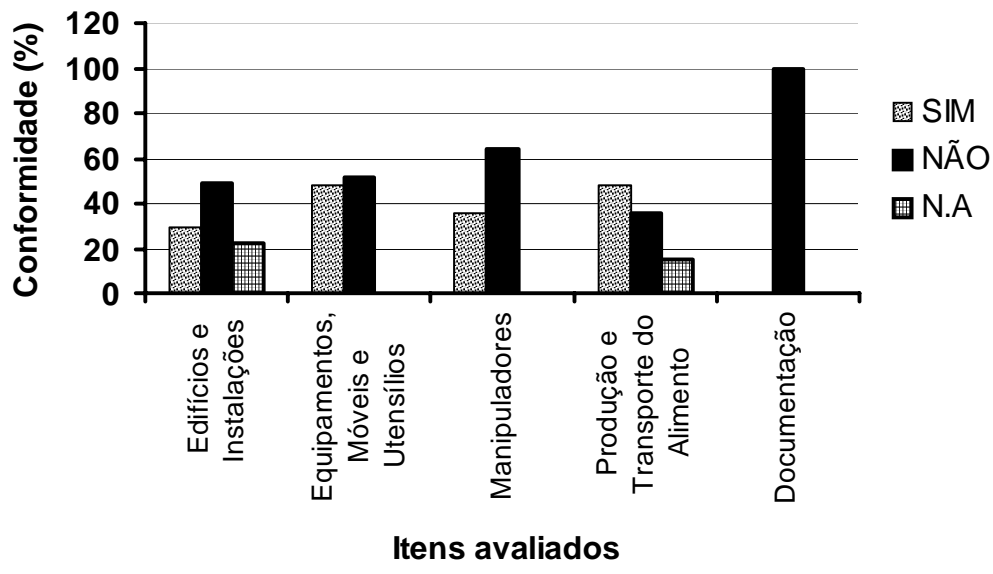

\section{FIGURA 2 - AVALIAÇÃO DOS ITENS RELACIONADOS ÀS BOAS PRÁTICAS DE FABRICAÇÃO NO ESTABELECIMENTO PROCESSADOR DO MUNICÍPIO DE BARBOSA FERRAZ (PR)}

NA = não avaliado

Baseado no diagnóstico inicial realizou-se a implantação das Boas Práticas de Fabricação, complementada com as análises microbiológicas em diferentes pontos do processo de pasteurização para detectar focos de contaminação.

De acordo com os resultados da Tabela 7, o leite cru contido no tanque de recepção apresentou valores acima de $2400 \mathrm{NMP} / \mathrm{mL}$ para coliformes totais e coliformes termotolerantes.

TABELA 7 - ENUMERAÇÃO DE COLIFORMES TOTAIS, COLIFORMES TERMOTOLERANTES E ESTAFILOCOCOS COAGULASE POSITIVA (ECP) EM DIFERENTES PONTOS DO PROCESSO DE PASTEURIZAÇÃO DO LEITE

\begin{tabular}{lccc}
\hline \multicolumn{1}{c}{ Amostras } & $\begin{array}{c}\text { Coliformes totais } \\
(\text { NMP/mL) }\end{array}$ & $\begin{array}{c}\text { Coliformes termotolerantes } \\
\text { (NMP/mL) }\end{array}$ & $\begin{array}{c}\text { ECP } \\
\text { (UFC/mL) }\end{array}$ \\
\hline 1 Tanque de recepção & $>2400$ & $>2400$ & $6 \times 10^{4}$ \\
\hline 2 Saída do pasteurizador & $<3$ & $<3$ & - \\
\hline 3 Entrada do tanque isotérmico & $<3$ & $<3$ & - \\
\hline 4 Saída do tanque isotérmico & $<3$ & $<3$ & - \\
\hline 5 Saída da embaladeira & 43 & 23 & - \\
\hline 6 Leite pasteurizado & 460 & 240 & $4 \times 10^{3}$ \\
\hline
\end{tabular}


Segundo TRONCO (2003), em diversos trabalhos realizados sobre contagem bacteriana, quase 95\% das contagens microbianas elevadas em leite cru são provenientes de problemas de deficiência na lavagem e sanitização dos equipamentos e utensílios de ordenha, falta de higiene na ordenha e sistema de resfriamento inadequado.

Após passar pelo tanque de recepção, o leite é clarificado e depois pasteurizado. Nos pontos 2, 3 e 4 (Tabela 7), os valores encontrados para coliformes termotolerantes estão abaixo de 3 NMP/ $\mathrm{mL}$, apresentando conformidade com os valores máximos estipulados para leite pasteurizado tipo $\mathrm{C}$ de $4 \mathrm{NMP} / \mathrm{mL}$ (BRASIL, 2001) e $2 \mathrm{NMP} / \mathrm{mL}$ (BRASIL, 2002a).

Em relação ao mapeamento, a provável origem da contaminação por coliformes localiza-se após a saída do tanque isotérmico, pois verificou-se que a partir desse ponto ocorreu a recontaminação. A enumeração de coliformes termotolerantes na saída da embaladeira e no leite já empacotado foi de 23 e $240 \mathrm{NMP} / \mathrm{mL}$, respectivamente.

Conforme SILVA, JUNQUEIRA e OLIVEIRA (1997), a presença de coliformes totais e coliformes termotolerantes em alimentos processados é considerada indicação útil de contaminação póssanitização ou pós-processo, evidenciando práticas de higiene e sanificação aquém dos padrões requeridos para o processamento de alimentos.

Na Figura 3 é possível observar o fluxograma das etapas que constituem o processo de pasteurização do leite, bem como os pontos analisados neste trabalho. Conforme mostram os resultados, o ponto destacado, ou seja, a embaladeira na operação de envase foi considerada um dos focos de contaminação do leite pasteurizado.

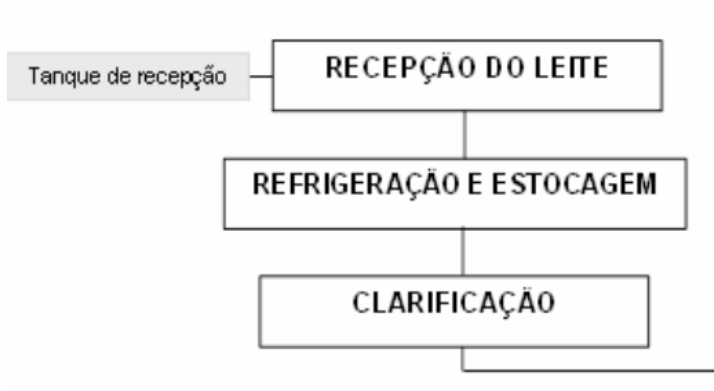

PONTOS ANALISADOS

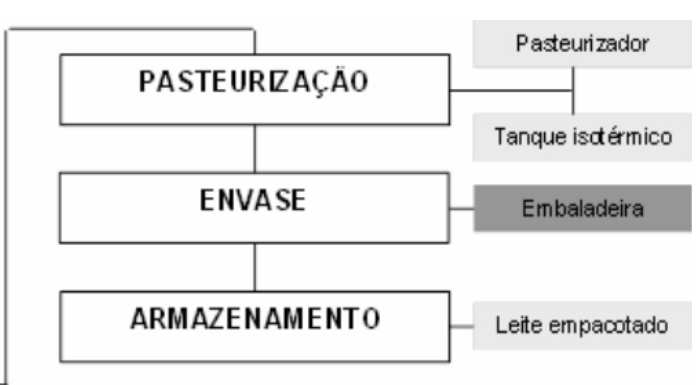

PONTO DE CONTAMINACÄO

\section{FIGURA 3 - IDENTIFICAÇÃO DOS PONTOS DE CONTAMINAÇÃO NO PROCESSO DE PASTEURIZAÇÃO DO LEITE}

Os resultados das análises de coliformes totais e coliformes termotolerantes para embalagens alcançaram de 240 e $43 \mathrm{NMP} / \mathrm{cm}^{2}$, respectivamente. Essa contaminação pode ter ocorrido devido ao armazenamento em local impróprio e manipulação inadequada das embalagens antes e durante 0 processamento, devendo ser considerado como ponto de contaminação no processamento do leite pasteurizado.

A Tabela 7 mostra que o valor encontrado na enumeração de estafilococos coagulase positiva (ECP) no leite pasteurizado foi de $4 \times 10^{3} \mathrm{UFC} / \mathrm{mL}$. Segundo JAY (2005) para que haja produção de enterotoxinas em concentração suficiente para causar doença é necessária contagem acima de $10^{4}$ ou $10^{5} \mathrm{UFC} / \mathrm{mL}$ e na legislação vigente não existem padrões para ECP para leite cru e pasteurizado.

A partir dos resultados obtidos, medidas corretivas foram tomadas visando eliminar os pontos de contaminação identificados. Essas medidas consistiram na implantação de Boas Práticas de Fabricação complementadas pelos Procedimentos Padrão de Higiene Operacional e a realização de treinamentos regulares de forma a conscientizar os colaboradores envolvidos sobre a necessidade de produzir alimentos de qualidade e seguros. 


\section{CONCLUSÃO}

Demonstrou-se com os resultados obtidos nas análises microbiológicas das amostras coletadas nas propriedades produtoras de leite, a eficácia da adoção das Boas Práticas de Produção na redução da contaminação microbiológica do leite cru e o papel fundamental dessas práticas na adequação do produtor rural à legislação vigente.

No estabelecimento processador de leite pasteurizado tipo $C$ verificou-se a não conformidade com as normas de Boas Práticas de Fabricação e condições higiênico-sanitárias insatisfatórias das amostras de leite pasteurizado provenientes da saída da embaladeira e do leite empacotado. Essa constatação deveu-se à presença de coliformes termotolerantes em valores acima do permitido pela legislação vigente e contaminação por estafilococos coagulase positiva, concluindo-se que a provável origem da contaminação estava localizada na embaladeira.

Confirmou-se a necessidade de adequação do estabelecimento processador às normas de Boas Práticas de Fabricação para produzir leite de qualidade tanto para consumo na fase adulta quanto para crianças beneficiadas pelo programa "Leite das Crianças".

Com o desenvolvimento do presente trabalho promoveu-se a melhoria da qualidade na cadeia produtiva do leite do município de Barbosa Ferraz (Paraná).

\section{ABSTRACT}

\section{AN APPROACH OF UNIVERSITY EXTENSION TO IMPROVE THE MILK QUALITY FROM THE CITY OF BARBOSA FERRAZI PARANÁ (BRAZIL) PRODUCTION CHAIN}

The goal of the present study was to promulgate hygiene practices and evaluate their efficiency in reducing the microbiologic contamination of milk. It was draw the map of the pasteurized milk processing line to identify the main contamination points and eliminate them adopting of Good Manufacturing Practices (GMP). A data assessment was undertaken in milk farms (17 units) and at processing establishment using checklists. A training course was provided at the milk farms with emphasis on the Good Production Practices following collection of raw milk, swab of milkers' hands surface and of the storage recipients (canisters) for microbiological analysis, before and after implementation of hygiene practices. In the processing establishment, five samples of milk were collected in different stages of the processing line as well as one pack of Type $C$ pasteurized milk. The results revealed that from the 9 items related to hygiene, 5 of them (55\%) showed non-conformity with the Brazilian Law. The samples collected before implementation of the hygiene practices presented a high microbiological contamination, whereas after such implementation, a reduction was confirmed. Application of check-list to assess the Good Manufacturing Practices at processing establishment evaluated 142 items, but only $38 \%$ were in conformity. The probable origin of contamination was located after the exit of the isothermal tank for pasteurized milk. The efficiency of adoption of Good Production Practices was confirmed by reduction of microbiological contamination of the raw milk as well as the need to adequate the processing establishment to the Good Manufacturing Practices.

KEY-WORDS: MILK; FOOD SAFETY; GOOD MANUFACTURING PRACTICE; MICROBIOLOGICAL CONTAMINATION.

\section{REFERÊNCIAS}

1 ARCURI, E.F.; BRITO, M.A.V.P.; BRITO, J.R.F.; PINTO, S.M.; ÂNGELO, F.F; SOUZA, G.N. Qualidade microbiológica do leite refrigerado nas fazendas. Arq. Bras. Med. Vet. Zootec., v.58, n. 3, p.440-446, jun. 2006.

2 BORELLI, B.M. Melhoria da qualidade do queijo Minas artesanal. Belo Horizonte: Fundação Centro Tecnológico de Minas Gerais (CETEC), 2006. 19 p.

3 BRASIL. Ministério da Saúde. Agência Nacional de Vigilância Sanitária. Resolução RDC n. 12, de 2 de janeiro de 2001. Regulamento técnico sobre padrões microbiológicos para alimentos. Diário Oficial [da] República Federativa do Brasil, Brasília, 10 de janeiro de 2001, n.7-E, p. 45.

4 BRASIL. Ministério da Agricultura, Pecuária e Abastecimento. Instrução Normativa n. 51 de 18 de setembro de 2002. Regulamentos técnicos de produção, identidade e qualidade do leite tipo $A$, do leite tipo $B$, do leite tipo $C$, do leite pasteurizado e do leite cru refrigerado e o regulamento técnico da coleta de leite cru refrigerado e seu transporte a granel. Diário Oficial [da] República Federativa do Brasil, Brasília, 29 de setembro de 2002ª, seção 1. 
5 BRASIL. Ministério da Saúde. Agência Nacional de Vigilância Sanitária. Resolução RDC n. 275 de 21 de outubro de 2002. Dispõe sobre o regulamento técnico de procedimentos operacionais padronizados aplicados aos estabelecimentos produtores/industrializadores de alimentos e a lista de verificação das boas práticas de fabricação em estabelecimentos produtores/industrializadores de alimentos. Diário Oficial [da] República Federativa do Brasil, Brasília, 23 de outubro de 2002b. Seção 1.

6 DOWNES, F. P.; ITO, H. (ed.). Compendium of methods for the microbiological examination of foods. Washington: American Public Health Association (APHA), 2001. 676 p.

7 DÜRR, J.W. Como produzir leite de alta qualidade. Brasília: Senar, 2005. 28 p.

8 FERREIRA, M.A. Controle de qualidade físico-químico em leite fluído. Brasília: Centro de Apoio ao Desenvolvimento Tecnológico da Universidade de Brasília (CDT/UnB), 2007. 17 p.

9 FRANCO, B.D.G.M.; LANDGRAF, M. Microbiologia dos alimentos. São Paulo: Atheneu, 2002. 182 p.

10 HAJDENWURCEL, J.R. Atlas de microbiologia de alimentos. São Paulo: Fonte Comunicações e Editora, 1998. v.1.

11 JAY, J.N. Microbiologia de alimentos. Porto Alegre: Artmed, 2005. 711 p.

12 LOPES, R.L.T. Fontes de contaminação de alimentos. Belo Horizonte: Fundação Centro Tecnológico de Minas Gerais (CETEC), 2007. 26 p.

13 OLIVEIRA, C.A.F.; FONSECA, L.F.L.; GERMANO, P.M.L. Aspectos relacionados à produção que influenciam a qualidade do leite. Higiene Alimentar, v.13, n.62, p.10-13, 1999.

14 PEREIRA, G.F.; MADEIRA, M.C.B.; LIMA, C.A.C. Ordenha higiênica. Natal: Empresa de Pesquisa Agropecuária do Rio Grande do Norte (EMPARN), 2006. 21 p.

15 SILVA, N.; JUNQUEIRA, V.C.A.; SILVEIRA, N.F.A. Manual de métodos de análise microbiológica de alimentos. São Paulo: Varela, 1997. 296 p.

16 TRONCO, V. M. Manual para inspeção da qualidade do leite. 2. ed. Santa Maria: UFSM, 2003. 49 p. 